\section{Integrated Diagnoses for an Integrated Treatment in a Suicide Attempt: A Case Report}

\section{Abstract}

Several authors agree that Diagnostic and Statistical Manual for Mental Disorders (DSM) is not appropriate to define a psychiatric diagnosis, with negative implications in research and treatment. Operative diagnosis is a strategic construct, it can be functional, complementary and coexists next to the DSM dictated descriptive diagnosis. While the latest ones can be used as a guide in emergency and during psychiatric hospitalization, especially to decidean adequate pharmacological treatment, the operative diagnosis can vice versa be useful to discover how a problem works and to indicate possible solutions in the long-term prognosis. The aim of this case report is to show the importance of an operative diagnosis, based also on integration of environmental and familial situation, to reach a better therapeutic effectiveness and recovery.

Keywords: Suicide; Psychiatric; Diagnosis; Personality Disorder

Received: May 11, 2019; Accepted: May 24, 2019; Published: May 31, 2019

\section{Andrea Agugliaa, ${ }^{1,}$, Luca Proietti ${ }^{1,2}$, Andrea Vallarino ${ }^{3}$ and Mario Amore ${ }^{1,2}$}

1 Psychiatric Clinic, IRCCS Ospedale Policlinico, San Martino, Genoa, Italy

2 Department of Neuroscience, Rehabilitation, Ophthalmology, Genetics, Maternal and Child Health, University of Genoa, Genoa, Italy

3 Faculty of Medicine, University of Genoa, Genoa, Italy

\section{*Corresponding author: Andrea Aguglia}

$\equiv$ andrea.aguglia@unito.it

Psychiatric Clinic, IRCCS Policlinico, San Martino Hospital, San Martino, Genoa, Italy.

Tel: +39010 5553314

Citation: Aguglia A, Proietti L, Vallarino A, Amore M (2019) Integrated Diagnoses for an Integrated Treatment in a Suicide Attempt: A Case Report. Clin Psychiatry Vol.5 No.2:1

\section{Introduction}

In psychiatric ward and in emergency situations, it's necessary to assess a patient according to DSM diagnosis, subsequently, at the time of rehabilitation or at the person's reintegration into family or into life environment, the concept of action research of Kurt Lewin is more useful. In the construction of physiological realities, the intervention diagnosis allows to get out of the DSM rigidity, preventing the patient to become chronic, avoiding inauspicious diagnostics labels or the so called labeling $[1,2]$.

As Karl Klaus says, "diagnosis is one of the most common diseases", especially in the field of psychiatry whereas overdiagnosis is prevalent.

An authoritative and above suspicion voice, as that of Allen F [3], reported the proofs of the diagnostic inflation, underlining the way of some psychiatric disorders, such as the bipolar disorder, autism, attention deficit disorder, had a statistical increase up to forty times in the last fifteen years, a real epidemic, based on inflated data, like anxiety disorders and depression, feeding, as a consequence, the pharmaceutical industries.

During rehabilitation and reintegration into society, it's necessary to make a distinction between medical, psychiatric and psychological diagnoses. "A sound medical diagnosis describes and indicates the therapy. A bronchitis diagnosis is heralding of good news for the patient, because the bronchitis is curable: I describe your disease, which means I have understood, therefore I know how to cure you. But the diagnosis have also different effects from descriptions. In psychiatry the diagnosis doesn't describe the disorder, but makes it up. It's the labeling phenomena" [4]. One of the most flashing examples is explained by David L Rosenhan [5]. A group of eight fake-patients (psychologists and psychiatrists) who, for research purposes, decided to present themselves in different hospitals, showing psychiatric symptoms (they heard voices). They were all admitted in psychiatric ward. Few days later, they 
were supposed to reveal themselves for whom they were, that is "healthy subjects". Every time they were asked about their health, they exhibited their mental health, answering, as it actually was, that they were fine, that they did not hear voices, that they had no more any of the psychiatric symptoms, they were recovered for with the diagnosis of "schizophrenia", nor they had any other symptoms. This was totally useless, because all of them were discharged after numerous days and weeks of hospitalization with the confirmed diagnosis of "schizophrenia", although in remission. The only ones who noted the "faking" were the other patients, who individuated the "intruders" saying: "you're not mad, you're a professor; ...you're a journalist..., etc.'. A false label creates a true reality: the going of the psychiatric recovery, the chronic making." Operative diagnosis is a strategic construct that overcomes the objective knowledge conception introduced by the Positivism. Operative diagnosis can be functional, complementary and coexists next to the DSM dictated descriptive diagnosis [6]. It is structured upon the concept of operative consciousness introduced in philosophy by Ernst von Glasersfeld: we can know reality only after having changed it. Diagnosis about the functioning of the disorder can be extrapolated only after having treated the person, which means after having introduced changes in the system that make us able to understand how the system works. With regard to this, we followed the teaching of $\mathrm{H}$. von Foerster [7], who in "Observing Systems" established there was no discontinuity between observer and observed, for the observer was part of the observed system and a prior knowledge of the pathologic systems was not possible, if not only a posterior, after the intervention.

Using operative diagnosis allow to reach a better therapeutic effectiveness and research outcomes, since DSM diagnosis is inappropriated to define mental disorder [1-3,8].

The aim of this paper is to show the importance of using an opearative diagnosis to reach a complete remission and Restitutio Ad Integrum. DSM diagnosis and pharmacological treatment permit to gain a remission of acute symptoms and an initial recovery. An opearative diagnosis underlines the importance to consider also the familial and interpersonal context in which a patient lives. The intervention on these aspects is crucial to obtain the full recovery.

\section{Case Introduction}

We report the case of a young Italian woman 24 year-old diagnosed with a Major Depressive Episode (MDE) and narcissistic personality disorder. The patient accepted voluntarily to participate in the study (case report) and provided her written informed consent for the publication.

She was admitted to the emergency department for a suicide attempt. She caused herself a vertical stab wound in the left forearm after taking half bottle of delorazepam's drops. The interruption of a romantic relationship with her boyfriend could be considered the trigger. The patient was in the family house with her boyfriend, while he was sleeping and her parents were at work. Her father is a naval engineer and works in ship building and her mother is a state employee.

\section{Presenting complaints}

She reported an important anguish state, depression, emotional lability, reduced appetite and insomnia. No current psychotic symptoms (hallucinations or delusions) were present. The psychiatric visit, performed during the hospitalization, showed loneliness experiences, personal dissatisfaction and inner emptiness that she attributed to the difficult management of the future. She reported high academic and work expectations with subjective frustration feelings and depressive thinking due to difficulty to maintain attention and concentration to study. Furthermore, the patient affirmed having thoughts of teadium vitae, unspecific suicidal fantasies, not structured and not planned in an attempt.

\section{History}

The clinical history can be summarized as follows: she was born in Italy, attended the English school and then she went to Germany to study Medicine and Surgery. She was attending the fifth year of the course without any difficulty to complete the exams until the year before the suicide attempt. She finished a psychodynamic psychotherapy lasted two years, she suffered of two mildmoderate MDE, one of which was treated with escitalopram 10 mg daily successfully, she was never hospitalized before. The clinical and psychiatric history was negative for a substance use disorder, bipolar disorder or other Axis I diagnosis. Moreover, no other suicide attempts were found. No familiarity for psychiatric disorders.

\section{Assessment}

Several scale were administered Hamilton Depression Rating Scale, Hamilton Anxiety Rating Scale, Global Assessment Functioning, Beck Hopelessness Scale, Temperament Evaluation of Memphis, Pisa, Paris and San Diego-autoquestionnaire version (TEMPS-A) and Structured Clinical Interview for Axis II disorders.

\section{Case conceptualization}

Given the clinical presentation, we prescribed Olanzapine 10 $\mathrm{mg}$ and Delorazepam $2 \mathrm{mg}$ to address the anguish state, the emotional lability and insomnia. Moreover Olanzapine was prescribed also for known anti-aggressive and anti-impulsive characteristics. One week later, clinician decided to prescribe also antidepressant medication, used for the previous depressive recurrences (Escitalopram $10 \mathrm{mg}$ ), to treat the associated depressive state without any side effects.

\section{Course of treatment, assessment of progress and complicating factors}

After two weeks a good clinical response was obtained: depressive symptomatology was reduced, the anguish state and the anticonservative thoughts were well controlled, a better quality of sleep was obtained. The patient showed also a better insight of suicide attempt being aware of the reasons that led 
to hospitalization. Her dissatisfaction about the future willing and the high academic-work expectations remained. During the hospitalization we hypothize that relational conflicts with her parents can contribute to her symptomatology. Her dissatisfaction about the future willing and the high academic-work expectations affect her quality of life, predisposing to subsequent relapses but also limiting her in completing the universitary career.

\section{Treating barriers to recovery}

The patient was discharged after 20 days and she was recommended to a Brief Strategic psychotherapist [9], given also the relational conflicts with her parents. The psychotherapist supposed a hysterical situation with demonstrative suicide attempt. But the hypothesis was verified first, inviting parents in therapy already during the hospitalization. Parents, caught by senses of guilt, reported that the girl had a progressive trend to working and studying autonomy, which they thought was excessively forced. It was like as the family axiom toward independence had been interpreted by the girl in an excessive sacrificing way. The family development model was a sacrificial pattern with an educative evolution to the duties, which must always surpass pleasures. Duty was the family leitmotif. The girl exceeded by herself in this pattern.

The first intervention was freeing parents from guilt. The girl lived under pressure, therefore, the first step was to remove the pressure inside the family. Being in the grip of guilt, it was possible that parents increased their attempted educative solutions, putting further pressure upon the girl. This has been important to prepare homecoming of the young girl. At the moment of the return, the parents had the job to stop talking to the daughter about the problems she had. In Brief Strategic Therapy, this is a prescription called "conspiracy of silence, observing the behavior without intervention" [10]. If the girl was to become immediately active, they had to observe the behavior without restricting it, if she allowed herself to relax, they had to take notice of that and then report it to the therapist. By doing so, parents have been elevated to role of co-therapists. The intervention is thin, but fundamental, a small difference, that makes a large difference. From possible cause of problems, parents have been redefined as a resource for the solution for the situation of the daughter. A radical change of perspective, that has helped the therapy. Subsequently, the girl was visited for some time and it was recommended to her to look around herself at $360^{\circ}$, looking to spot the pleasing things for her, going from the most unrefined to the more refined ones, and report them all to the therapist. By doing this, we have reversed the family model from duty first and then pleasure to pleasure first and then duty. Given the ethical and religious severity of the family, we referred to S. Agustin, which goes "nobody can live on the earth without pleasure".

After all this, the girl was followed in psychotherapy for a short time in Italy, gradually reducing the drugs until completely interrupting the pharmacology therapy, and then returned to live abroad, where she is completing university education.

\section{Treatment implications of the case}

This case report demonstrates how an adequate therapeutic strategy based on not only pharmacological and psychological treatment but also on rehabilitation need to several tools according to different hospital, rehabilitative, familial and individual phases. Just like a capable surgeon knows how to use different tools according to the different phases of the therapeutic strategies, the same way in psychiatry and psychotherapy different points of view in different moments can be used. DSM diagnosis could not be totally appropriate to understand the clinical picture of a patient andto choose therapeutic options in post-acute phase.

\section{Discussion and Conclusion}

The same way in psychiatry and psychotherapy different points of view in different moments can be used, with different methodological bias to avoid [11]

It is necessary to use the psychiatric ideas not as walls to debate, but as different techniques that can communicate among them. DSM diagnosis can affect the therapeutic effectiveness and the research findings [1], we have to use other diagnostic constructs to understand the biological disfunction and psychological dynamics underlying a psychopathological syndrome.

In this case, psychiatric ward, public outpatients unit and private psychotherapists contributed to hit the person's goals in a short time and with ecological instruments. We could affirm that in addition to make known with patients, the professionals succeeded to communicate among them, putting in relation their different therapeutic knowledge.

This case, moreover, demonstrates how it is necessary to be capable of looking at the problems also from a direct and indirect systemic point of view. In this case especially, it has been important to involve parents into the therapeutic strategy.There is a frequent tendency to exaggerate in considering the patients as a Spinoza's monad, isolated from all and everyone and even to be prone to exclude with blame from the therapy the patient's relatives. From our point of view this is a mistake, because the parents could often represent an excellent resource for the patient's recovery $[12,13]$.

And never as in this moment parents are facing difficulties in being guides for the children for cultural and social reasons, that we haven't got time to analyze right now. Helping parents to help the children becomes [14], in this historical period, an additional fundamental work for the medical doctor.

To conclude, Hippocrates, on the other hand warned: "life is short, art is vast, opportunity transitory, experience fallacious, judgment difficult. Not only the medical doctor must do what is appropriate, but also the patient, those who assist him and all other people". 


\section{References}

1 Van Praag HM (2010) Biological psychiatry: still marching forward in a dead end. World Psychiatry 9: 164-165.

2 Pietrabissa G, Manzoni G, Gibson P, Boardman D, Gori A, et al. (2016) Brief strategic therapy for obsessive- compulsive disorder: a clinical and research protocol of a one-group observational study. BMJ Open 6: e009118.

3 Frances A (2013) Saving Normal: An Insider's Revolt against Outof-Control Psychiatric Diagnosis, DSM-5, Big Pharma, and the Medicalization of Ordinary Life. Psychother Aust 19: 14.

4 Valiakas G, Vallarino A (2015) In principio era il medico di famiglia, lo specialista di medicina generale, in Milanese, Milanese, II tocco, il rimedio, la parola. Ponte alle Grazie. Milano.

5 Rosenham DL (1973) On Being Sane in Insane Places. Science 179: 250-258.

6 Nardone G, Salvini A (2013) Dizionario Internazionale di Psicoterapia. Garzanti. Milano
7 Foerster HV (1987) Sistemi che osservano. Astrolabio Roma 213.

8 Van Praagh HM (2010) No functional psychopharmacology without functional psychopathology. Acta Psychiatr Scand 122: 438-439.

9 Nardone G, Watzlawick P (2005) Brief Strategic Therapy. Jason Aronson Inc, United States.

10 Nardone G, Balbi E (2008) Solcare il mare all'insaputa del cielo. Ponte alle Grazie, Milano.

11 Ludici A, Faccio E, Castelnuovo G, Turchi GP (2019) The Methodological Bias That Can Reduce (or Affect) the Process of Diagnostic Construction in Clinical Settings. Front Psychol 10: 157.

12 Szapocznik J, Muir JA, Duff JH, Schwartz SJ, Brown CH (2015) Brief Strategic Family Therapy: Implementing evidence-based models in community settings. Psychother Res 25: 121-133.

13 Horigian VE, Anderson AR, Szapocznik J (2016) Taking Brief Strategic Family Therapy from Bench to Trench: Evidence Generation Across Translational Phases. Fam Process 55: 529-542.

14 Nardone G (2012) Aiutare i genitori ad aiutare i figli. Ponte alle Grazie, Milano. 